\title{
Preparation and Characterization of a Chemically Sulfated Cashew Gum Polysaccharide
}

\author{
Érico de Moura Neto, Jeanny da S. Maciel, Pablyana L. R. Cunha, \\ Regina Célia M. de Paula and Judith P. A. Feitosa*
}

\author{
Departamento de Química Orgânica e Inorgânica, Universidade Federal do Ceará, \\ CP 6021, 60455-760 Fortaleza-CE, Brazil
}

\begin{abstract}
A goma do cajueiro (GC) foi sulfatada em piridina:formamida usando ácido clorossulfônico como reagente. A confirmação da sulfatação foi obtida por espectroscopia no infravermelho com transformada de Fourier (FTIR) pelo aparecimento da frequência de vibração em $1259 \mathrm{~cm}^{-1}$ devido ao estiramento assimétrico $\mathrm{S}=\mathrm{O}$. Os graus de sulfatação foram de $0,02,0,24$ e 0,88 , determinados pela percentagem de enxofre. Os dados de ressonância magnética nuclear (RMN) 1D e 2D mostram que a sulfatação ocorreu nos carbonos primários do polissacarídeo. Um aumento de no mínimo 4\% na viscosidade da solução foi observado após a sulfatação. Análise termogravimétrica (TGA) indica que o derivado é estável até cerca de $200^{\circ} \mathrm{C}$. A comparação entre os derivados sulfatados e carboximetilados foi feita no intuito de verificar a possibilidade de formação de complexos polieletrolíticos, já realizada com os carboximetilados.
\end{abstract}

Cashew gum (CG) was sulfated in pyridine:formamide using chlorosulfonic acid as the reagent. Confirmation of sulfation was obtained by Fourier transform infrared (FTIR) spectroscopy through the presence of an asymmetrical $\mathrm{S}=\mathrm{O}$ stretching vibration at $1259 \mathrm{~cm}^{-1}$. The degrees of substitution were $0.02,0.24$ and 0.88 determined from the sulfur percentage. 1D and 2D nuclear magnetic resonance (NMR) data showed that the sulfation occurred at primary carbons. An increase of at least $4 \%$ of the solution viscosity was observed due to sulfation. The thermal gravimetric curves (TGA) indicate that the derivatives are stable up to $c a .200{ }^{\circ} \mathrm{C}$. The sulfated $\mathrm{CG}$ is compared to carboxymethylated $\mathrm{CG}$ in order to verify the possibility of the use of the former in the preparation of polyelectrolyte complexes; the latter is already being used for this application.

Keywords: cashew gum, Anacardium occidentale, sulfation, NMR

\section{Introduction}

Sulfated carbohydrates are found in plants and animals. In plants, they occur in the intercellular and cell wall region of brown and red algae (fucoidan, carrageenan). ${ }^{1,2}$ Much attention has been focused on the physiological role of sulfated polysaccharides and many attempts have been made to synthesize sulfated polysaccharides to obtain new pharmacological agents with possible therapeutic uses, ${ }^{3}$ which are strictly related to the presence of polyanionic charges. ${ }^{4}$ Polyanions can also be used to obtain polyelectrolyte complexes with polycations, such as chitosan. These polyelectrolyte complexes (PECs) have been proposed for many applications including scaffolds for pulp cell regeneration and matrixes for protein carriers

*e-mail: judith@dqoi.ufc.br and antibiotics. ${ }^{5,6}$ The particle size, swelling and drug delivery behavior of PECs can be affected by the molecular parameters of oppositely charged polyelectrolytes. The formation of polyelectrolyte complexes (PECs) represents an easy way to produce various structures ranging from nanometer sizes (water-soluble aggregates and nanoparticles) to macroscopic states (physical gel and film). ${ }^{7}$

Brazil has approximately 680,000 ha planted with the cashew nut tree (Anacardium occidentale) and the average production of gum/tree/year is $700 \mathrm{~g},{ }^{8}$ with a potential annual cashew gum (CG) production of 50,000 tons. ${ }^{9}$ The gum from Ceará State has been characterized as a heteropolysaccharide containing (by wt.\%) the following neutral monosaccharides:galactose $(72-73 \%)$, glucose $(11-14 \%)$, arabinose (4.6-5.0\%) and rhamnose $(3.2-4.0 \%){ }^{10,11}$ The ionic charge of the gum is due to glucuronic acid, however, this has a low content 
(4.7-6.3 wt.\%). Different composition was found for gum from Pernambuco State: galactose (82\%), glucose $(6 \%)$, arabinose $(4 \%)$, rhamnose $(2 \%)$ and uronic acid $(5 \%) .^{12}$ Independent of the origin, CG is mainly composed of three types of galactan units within the core, linked by C-1 and C-3, C-1 and C-6 and C-1, C-3 and C-6..$^{10,11}$ Modifications have been carried out to cashew gum in order to increase its ionic charge in the carboxylate group, such as carboxymethylation ${ }^{13}$ and oxidation with TEMPO reagent. ${ }^{14}$ An overcharged new polysaccharide (carboxymethylated) has been used in the preparation and characterization of polyelectrolyte complex nanoparticles with chitosan to identify their application as a drug delivery system. ${ }^{15}$

In this study, sulfated derivatives of cashew gum were synthesized and characterized in order to obtain a more charged polyelectrolyte than the original gum through the introduction of a new chemical group, $-\mathrm{OSO}_{3} \mathrm{Na}$. The polyelectrolyte properties were compared with those of carboxymethylated CG, ${ }^{13}$ which were already used in the preparation of nanoparticles of PECs,,$^{15}$ to verify the possibility of obtaining polyelectrolyte complexes with sulfated CG.

\section{Experimental}

\section{Origin and purification}

Crude samples of CG were collected from native trees from Fortaleza (Ceará State, Brazil). They were purified as a sodium salt using a previously described method. ${ }^{11,16}$ Nodules free of bark were selected and dissolved in distilled water at room temperature to give a $5 \%(\mathrm{~m} / \mathrm{v})$ solution. The solution $\mathrm{pH}$ was adjusted to $c a$. 7.0 by addition of diluted aqueous $\mathrm{NaOH}$. The clear solution was successively filtered through sintered glass and the polysaccharide precipitated with ethanol.

\section{Sulfation}

The sulfation procedure was based on the methodology described by O'Neill ${ }^{17}$ and Ono et al. ${ }^{18}$ with modifications. This method uses chlorosulfonic acid (CSA) as the sulfation agent. CSA is a versatile reagent widely ${ }^{19}$ and recently $y^{4,21-24}$ used in the sulfation of polysaccharide. The purified cashew gum sample $(1 \mathrm{~g})$ was swelled in pyridine:formamide (60:75 mL) with stirring at $25^{\circ} \mathrm{C}(12 \mathrm{~h})$. The solution was cooled to $4{ }^{\circ} \mathrm{C}$ and CSA was dropped into the mixture over a period of $30 \mathrm{~min}$. The mixture was kept at this temperature overnight. The procedure was performed with the following acid volumes 2,6 and $8 \mathrm{~mL}$ to obtain different CG gum/CSA molar ratios. The resulting solution was neutralized with $\mathrm{NaHCO}_{3}$, dialyzed against water for 3 days and freeze dried. The solid product was dissolved in water and precipitated with 2 volumes of ethanol. The samples were denoted as CGS2, CGS6 and CGS8, with the number corresponding to the volume of CSA.

\section{Measurements}

The contents of nitrogen, carbon and sulfur were determined for the sulfated cashew gum (CGS) by elemental microanalysis using a Perkin-Elmer CHN 2400 instrument.

Fourier transform infrared (FTIR) spectra were recorded with $\mathrm{KBr}$ pellets on a FT-IR Shimadzu 8300 spectrophotometer.

1D $\left({ }^{1} \mathrm{H}\right.$ and ${ }^{13} \mathrm{C}$ broad band, BB) and $2 \mathrm{D}\left({ }^{1} \mathrm{H}-{ }^{13} \mathrm{C}\right.$ heteronuclear single-quantum correlation, $\mathrm{HSQC}$ ) spectra of $3 \%(\mathrm{~m} / \mathrm{v})$ solutions in $\mathrm{D}_{2} \mathrm{O}$ at $343 \mathrm{~K}$ were recorded on a Fourier transform Bruker Avance DRX 500 spectrometer. An inverse multinuclear gradient probe-head equipped with z-shielded gradient coils, and with Unix Silicon Graphics workstation was applied. Sodium 2,2-dimethylsilapentane5 -sulfonate (DSS) was used as the internal standard $\left(0.00 \mathrm{ppm}\right.$ for $\left.{ }^{1} \mathrm{H}\right)$. A distortionless enhancement through the polarization transfer (DEPT 135) spectrum was recorded in order to determine the hydrogenation of each carbon.

Thermogravimetric analysis (TGA) of the samples were carried out using a Shimadzu TGA-50 instrument at a heating rate of $10^{\circ} \mathrm{C} \mathrm{min}^{-1}$ over the temperature range of $25-700^{\circ} \mathrm{C}$. The air flow rate was maintained at $50 \mathrm{~mL} \mathrm{~min}^{-1}$ and the initial sample mass was $10 \mathrm{mg}$.

The elution volumes were determined by gel permeation chromatography using a Shimadzu LC-10AD chromatograph with a refractive index detector RID-6A at room temperature using an Ultrahydrogel linear column $(7.8 \times 300 \mathrm{~mm})$, flow rate of $0.5 \mathrm{~mL} \mathrm{~min}{ }^{-1}$, polysaccharide solution concentration of $0.1 \%(\mathrm{~m} / \mathrm{v})$, water as the solvent and $0.1 \mathrm{~mol} \mathrm{~L}^{-1} \mathrm{NaNO}_{3}$ as the eluent. The sample volume was $50 \mu \mathrm{L}$.

Rheological studies of CG and CGS aqueous solutions $(1 \%, \mathrm{~m} / \mathrm{v})$ were performed on a Rheometer AR550 (TA instruments) at $25{ }^{\circ} \mathrm{C}$ with $40 \mathrm{~mm}$ cone plate sensor. The effect of shear rate on the solution viscosity was evaluated.

\section{Results and Discussion}

Effect of chlorosulfonic acid concentration on yield and degree of sulfation

The degree of sulfation (DS) obtained in reactions with different CSA volumes was determined. The DS is defined 
as the average number of $-\mathrm{OSO}_{3} \mathrm{Na}$ groups inserted in each monosaccharide unit. As the main constituents of cashew gum are hexoses, ${ }^{10}$ the DS was considered as the number of $-\mathrm{OSO}_{3} \mathrm{Na}$ groups per 6 carbons. From data on the $\mathrm{S}$ and $\mathrm{C}$ content, it is possible to calculate the DS, in a similar way to that used by Melo et al. ${ }^{25}$ The CG contains $1 \%$ of protein with $c a$. $70 \%$ of amino acid without sulfur. ${ }^{26}$ The $\mathrm{S}$ content from protein was very low and its contribution in the calculus insignificant. Hence, the DS of sulfated cashew gum can be determined using $\mathrm{C}$ and S\% through equation 1.

$\mathrm{DS}=\frac{\left(\frac{\mathrm{S} \%}{\text { atomic mass of } \mathrm{S}}\right)}{\left(\frac{\mathrm{C} \%}{\text { atomic mass of } \mathrm{C}}\right) 6}=2.25\left(\frac{\mathrm{S} \%}{\mathrm{C} \%}\right)$

Calculated DS are shown in Table 1. Different values for cashew gum derivatives were produced by varying the amount of sulfation reagent, SR, in this case chlorosulfonic acid. For cashew gum, the DS increases with the SR/sugar unit (SR/SU) ratio. A similar trend has been observed for the sulfation of polysaccharides from seeds of Lupinus polyphyllus ${ }^{27}$ and cellulose, ${ }^{23}$ but only up to SR/SU ratios of 2.6 and 4.5 , respectively. At a higher sulfation reagent/ polysaccharide ratio, a lower DS was observed for both polysaccharides.

With the comparison of DS of different polysaccharides at similar SR/SU ratios (Table 1), it can be concluded that the reaction conditions applied to the cashew gum led to a less efficient sulfation than that reported by other authors. ${ }^{23,28}$ This result could be attributed to the polysaccharide concentration and temperature, being lower than that applied in the other studies (temperature above $30^{\circ} \mathrm{C}$ and polysaccharide concentration greater than $5 \%$ ), as well as the use of different sulfation agents. A temperature of $4{ }^{\circ} \mathrm{C}$ has been adopted in the case of cashew gum in order to avoid serious degradation of the polysaccharide. ${ }^{17}$ When the same temperature, polysaccharide concentration and solvents were utilized, DS values of 0.50 and 0.62 were obtained by Ono et al. ${ }^{18}$ even with a greater sulfation reagent concentration $(\mathrm{SR} / \mathrm{SU}=31.6)$.

The reaction yields obtained for different CSA volumes are also listed in Table 1. An increase in the amount of CSA promoted a significant decrease in the sulfation yield. The comparison of the reaction yields of cashew gum and of other gum derivatives obtained using similar methodology was not possible, since this information was not available in either of the reports by $\mathrm{O}^{\prime} \mathrm{Neill}^{17}$ and Ono et al. ${ }^{18}$ The apparent yields of more than $100 \%$ were reported by Geresh et al..$^{29}$ in the sulfation of extracellular polysaccharides of red microalgae. In this case, although not specified, the yields were calculated as the mass of sulfated product in relation to the initial mass of polysaccharide. However, the more precise yields are those calculated taking into account that the introduction of each $-\mathrm{SO}_{3} \mathrm{Na}$ group causes an increase of $102 \mathrm{~g} \mathrm{~mol}^{-1}$. In the case of cashew gum, galactose is the major constituent. ${ }^{10}$ Therefore, the final molar mass of sulfated product is expected to be $162+\mathrm{DS} \times 102 \mathrm{~g} \mathrm{~mol}^{-1}$, where $162 \mathrm{~g} \mathrm{~mol}^{-1}$ is the molar

Table 1. Comparison between the sulfation reaction conditions and the characteristics of the obtained polysaccharide derivatives

\begin{tabular}{|c|c|c|c|c|c|c|c|}
\hline Sample & $\begin{array}{c}\text { Polysaccharide conc. / } \\
\qquad(\% \mathrm{~m} / \mathrm{v})\end{array}$ & Sulfation reagent & $\mathrm{SR} / \mathrm{SU}^{\mathrm{a}}$ & $\begin{array}{c}\text { Temperature / } \\
{ }^{\circ} \mathrm{C}\end{array}$ & $\begin{array}{l}\text { Yield }^{\mathrm{b}} / \\
(\mathrm{g} \%)\end{array}$ & DS & Ref. \\
\hline \multirow{4}{*}{ Pullulan } & 20 & $\mathrm{SO}_{3}$-py & 4 & 60 & 91 & 1.50 & \multirow{4}{*}{ Mihai et al. ${ }^{28}$} \\
\hline & 20 & $\mathrm{SO}_{3}$-py & 4 & 80 & 90 & 1.22 & \\
\hline & 20 & $\mathrm{SO}_{3}-\mathrm{DMF}$ & 4 & 60 & 42 & 1.32 & \\
\hline & 20 & $\mathrm{SO}_{3}$-DMF & 4 & 80 & 6 & 1.22 & \\
\hline \multirow{4}{*}{ Cellulose $^{\mathrm{c}}$} & 5 & CSA-DMF & 1.5 & 30 & 67 & 0.52 & \multirow{4}{*}{ Wang et al $^{23}$} \\
\hline & 5 & CSA-DMF & 3.0 & 30 & 36 & 1.93 & \\
\hline & 5 & CSA-DMF & 4.5 & 30 & 32 & 2.01 & \\
\hline & 5 & CSA-DMF & 6.0 & 30 & 35 & 1.53 & \\
\hline \multirow{3}{*}{ Epimedium polysaccharide $^{d}$} & 2 & CSA-py & 0.86 & 60 & 20 & 1.12 & \multirow{3}{*}{ Lu et al..$^{22}$} \\
\hline & 2 & CSA-py & 0.86 & 80 & 16 & 0.83 & \\
\hline & 2 & CSA-py & 0.86 & 95 & 39 & 0.35 & \\
\hline \multirow{3}{*}{ Cashew gum } & CGS2 & CSA-py-FA & 4.9 & 4 & 53 & 0.02 & \multirow{3}{*}{ this study } \\
\hline & CGS4 & CSA-py-FA & 14.6 & 4 & 26 & 0.24 & \\
\hline & CGS8 & CSA-py-FA & 19.4 & 4 & 15 & 0.88 & \\
\hline
\end{tabular}

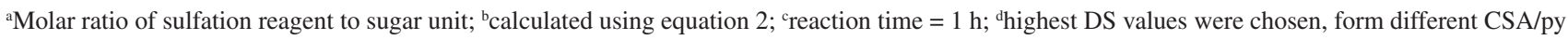
ratios, $\mathrm{CSA}=$ chlorosulfonic acid, $\mathrm{py}=$ pyridine, $\mathrm{DMF}=$ dimethylformamide and $\mathrm{FA}=$ formamide. 
mass of the linked galactose units. Equation 2 expresses the most appropriate way to calculate the yield (\%):

Yield $=100 \frac{\mathrm{m}_{\text {final }}}{\left[1+\left(\frac{\mathrm{DS} 102}{162}\right)\right] \mathrm{m}_{\text {inicial }}}$

where $\mathrm{m}_{\text {final }}$ and $\mathrm{m}_{\text {inicial }}$ are the mass of sulfated product and of polysaccharide, respectively.

There are many methods which can be used to sulfate polysaccharides, for instance, employing sulfuric acid, sulfur trioxide-pyridine, sulfur trioxidedimethylformamide, chlorosulfonic-pyridine (py) or chlorosulfonic-pyridine-formamide. A comparison of the obtained yields from different methods applied to polysaccharides is shown in Table 1 . The reaction conditions are very diverse in terms of polysaccharide concentration, molar ratio of sulfation reagent to sugar unit, time and temperature of reaction, sulfation agent and solvent. The cashew gum sulfation was carried out with the lowest gum concentration, highest $\mathrm{SR} / \mathrm{SU}$ ratio and lowest temperature. The obtained yield for the sulfation of $\mathrm{CG}$ is in the range of those reported for cellulose and epidemium polysaccharide using CSA as the sulfation agent (16-67\%). ${ }^{22,23} \mathrm{~A}$ higher yield was registered for pullulan sulfated with $\mathrm{SO}_{3}$-pyridine, but a much more concentrated polysaccharide solution was used. ${ }^{28} \mathrm{~A}$ lower yield at higher concentrations of chlorosulfonic acid was observed for cashew gum and may be attributed to degradation of the polysaccharide chain.

DS is an important parameter in terms of PEC formation because the charge density is the main driving force of the reaction. In addition, the particle size of PECs was influenced by the molar ratio of cationic to anionic units. ${ }^{30}$ Carboxymethylated cashew gum derivatives with DS values of 0.16 and 0.36 were used to obtain nanoparticles of PEC with chitosan. ${ }^{15}$ The authors observed that the particle size increased with DS. The sulfated cashew gum derivatives showed the same range of negative charge as that observed for carboxymethylated CG. The formation of nanoparticles of CGS with chitosan is expected, but the dependence on DS is different due to the diverse polysaccharide conformation, which will be the subject of further research.

\section{Infrared spectroscopy}

The presence of sulfate groups in CGS was identified by comparing the FTIR spectra of CG and CGS derivatives (Figure 1). The spectrum for the sulfated cashew gum shows a new band at $1259 \mathrm{~cm}^{-1}$, attributed to the asymmetrical

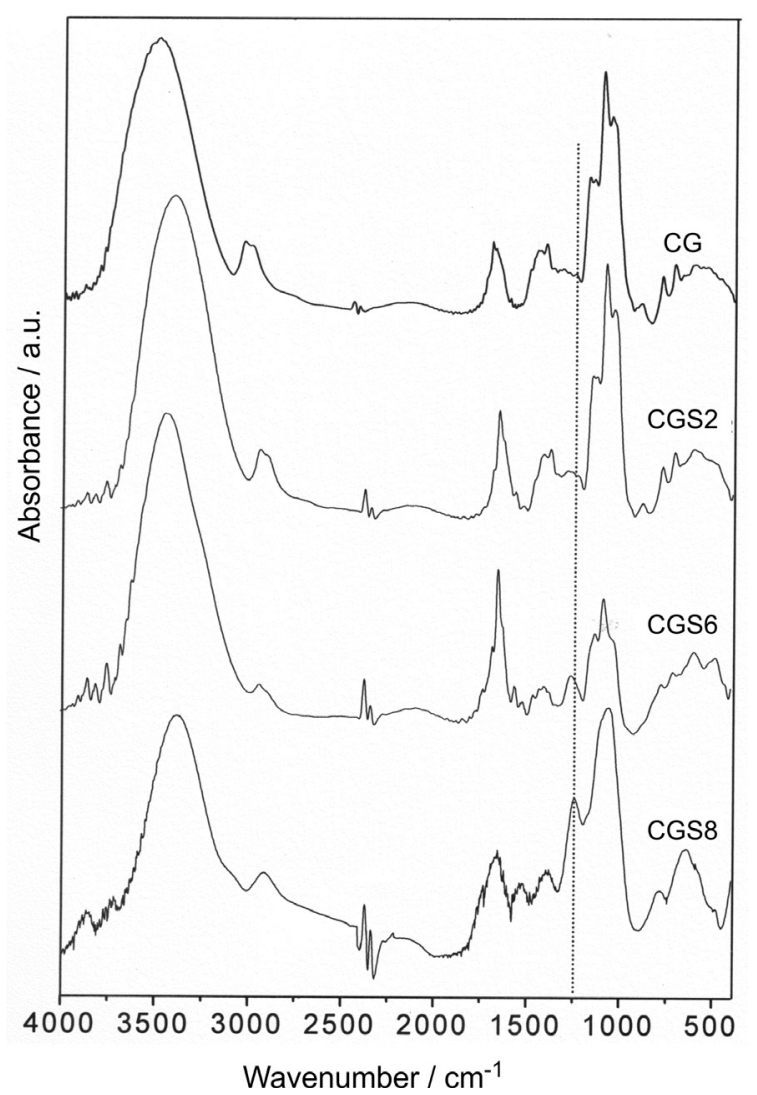

Figure 1. Infrared spectra obtained for unmodified (CG) and sulfated cashew gums (CGS2, CGS6 and CGS8).

stretching of the $\mathrm{S}=\mathrm{O}$ vibration..$^{31}$ This new band appears for all sulfated samples and becomes more intense as the DS increases, from CGS2 to CGS8. The profile of the 900-600 $\mathrm{cm}^{-1}$ region for the CGS6 and, particularly, for the CGS8 gums, seems to differ from that of the CG. For cashew gum, the bands at $775 \mathrm{~cm}^{-1}$ can be assigned to the $\mathrm{C}-\mathrm{O}-\mathrm{C}$ bending vibration, and those at 711 and $603 \mathrm{~cm}^{-1}$ to deformation and scaffold vibrations, respectively. ${ }^{31}$ For CGS, the band at $711 \mathrm{~cm}^{-1}$ disappears and the other two are shifted to higher wavenumbers (781 and $638 \mathrm{~cm}^{-1}$ ). A shift to higher values in the order of 10 to $40 \mathrm{~cm}^{-1}$ was also observed by Mahner et al. ${ }^{31}$ after sulfation of pullulan. This indicates that although not attributed directly to sulfate group vibration, the band shifts in the $800-600 \mathrm{~cm}^{-1}$ region are correlated to the sulfation.

\section{Nuclear magnetic resonance}

The ${ }^{13} \mathrm{C}$ BB NMR spectrum (Figure 2) for CG is similar to that obtained by de Paula et al. ${ }^{10}$ The ${ }^{1} \mathrm{H}-{ }^{13} \mathrm{C}$ HSQC spectrum for CG (Figure 3(a)) shows the correlation of previously assigned ${ }^{13} \mathrm{C}$ data ${ }^{11}$ with anomeric protons: $\alpha$-D-glucose $(\delta 4.95 / 100.7), \alpha$-L-rhamnose $(\delta 4.81 / 101.3)$, $\beta$-D-galactose $(1 \rightarrow 3)(\delta 4.69 / 104.1$ and $\delta 4.43 / 104.2)$, 
$\beta$-D-glucuronic acid $(\delta 4.55 / 103.8)$, and $\beta$-D-galactose $(1 \rightarrow 6)(\delta$ 4.39/105.0).

The ${ }^{13} \mathrm{C}$ BB NMR spectrum for CGS6 derivative (Figure 2) shows some differences in relation to unmodified gum. The anomeric signals decrease considerably due to glucose and rhamnose residue, probably because of the chain degradation. A new signal at $\delta 67.8$ is observed for CGS6 in comparison with the CG spectrum. In ${ }^{13} \mathrm{C}$ DEPT NMR spectrum (not shown), the signal at $\delta 68.7$ appeared with the opposite amplitude to those of $\mathrm{CH}_{3}$ and $\mathrm{CH}$, which can be attributed to the sulfation of $\mathrm{CH}_{2}$ primary carbons (C-6). The presence of a sulfate group causes an increase in the ${ }^{13} \mathrm{C}$ chemical shift of 6-8 ppm for the $\alpha$ carbons, and a shift of 0.4-0.7 ppm for protons. ${ }^{4,23,32}$ The ${ }^{1} \mathrm{H}-{ }^{13} \mathrm{C}$ HSQC NMR spectrum for CGS6 (Figure 3(b)) shows a correlation with $\delta 4.2 / 67.8$ (very small signal on the ${ }^{13} \mathrm{C} B B$ NMR spectrum), which confirms the substitution at $\mathrm{CH}_{2}(\mathrm{C}-6)$. Since protons H-6 from unsubstituted sugar residues occurred between 3.6 and $3.9 \mathrm{ppm}$ (Figure 3(a)), the new signal at $\delta 4.2$ indicates sulfation on the residues which have a primary group. ${ }^{32}$ The

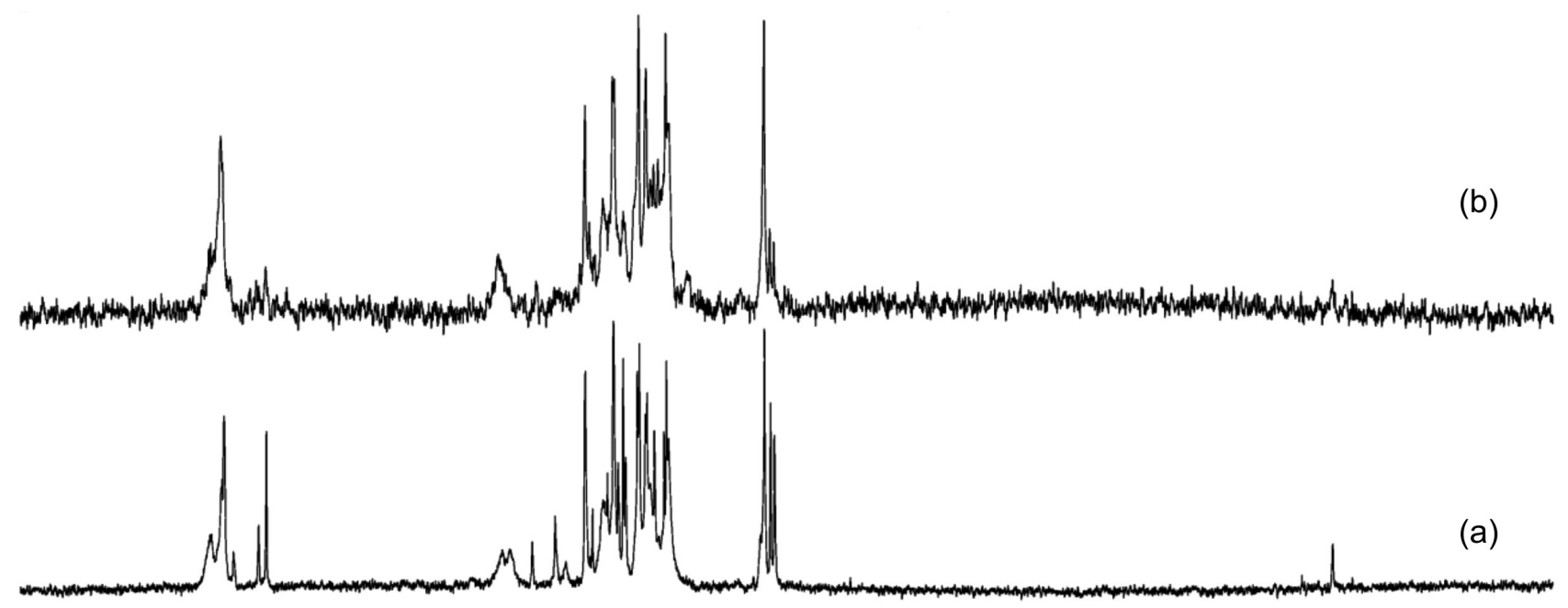

$\begin{array}{lllllllllllllllllllllllllll}115 & 110 & 105 & 100 & 95 & 90 & 85 & 80 & 75 & 70 & 65 & 60 & 55 & 50 & 45 & 40 & 35 & 30 & 25 & 20 & 15 & 10 & \text { ppm }\end{array}$

Figure 2. ${ }^{13} \mathrm{C}$ NMR spectra obtained for (a) unmodified cashew gum (CG) and (b) sulfated cashew gum (CGS6).
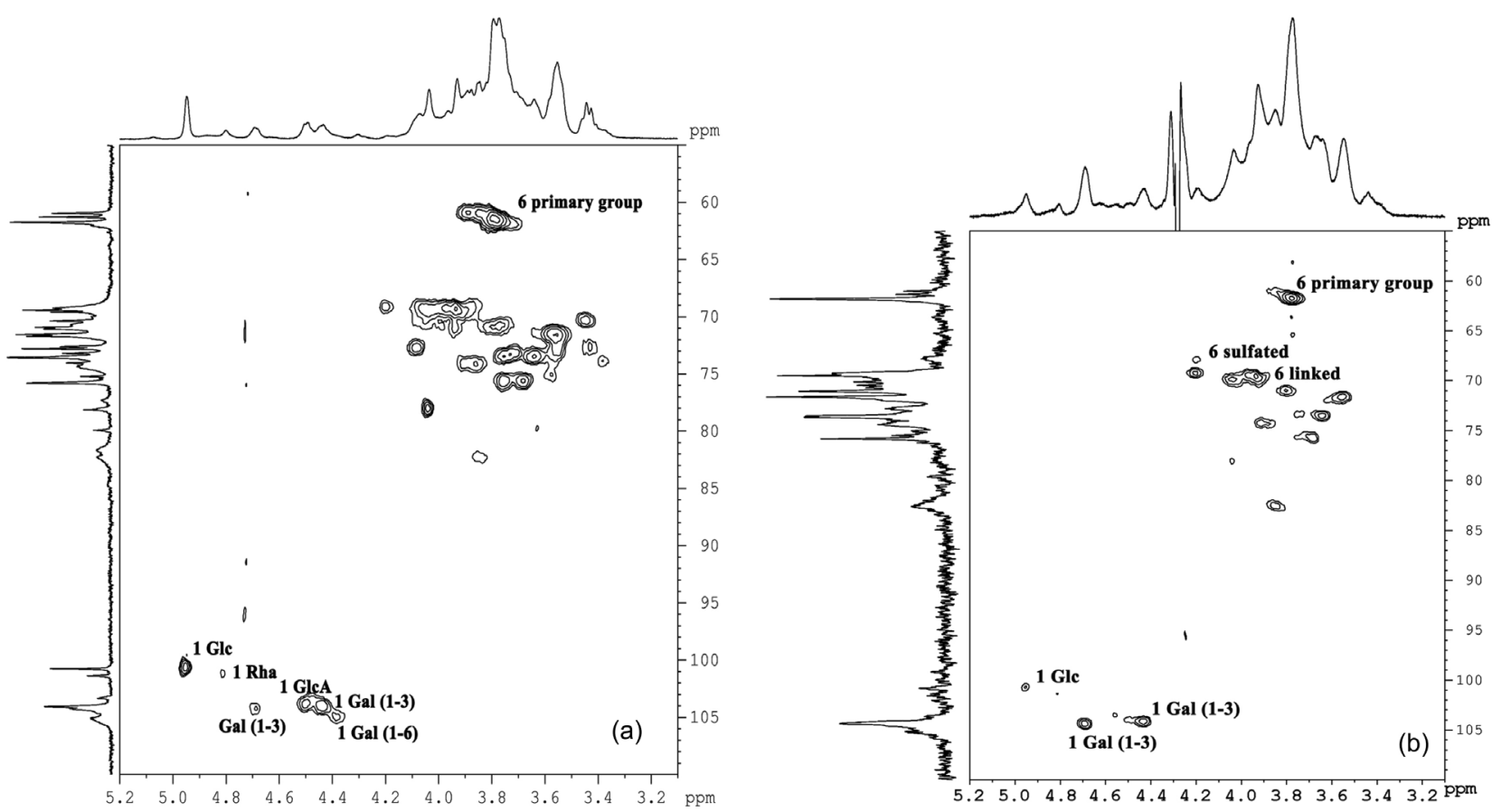

Figure 3. ${ }^{1} \mathrm{H}-{ }^{13} \mathrm{C}$ HSQC spectra obtained for (a) unmodified cashew gum (CG) and (b) sulfated cashew gum (CGS6). 
DEPT 135 NMR spectrum for CGS6 (see Supplementary Information) and the HSQC NMR experiment (Figure 3(b)) indicate that 6-O-substituted galactose units $(\delta$ 4.03/70.3) remain after the sulfation reaction.

\section{Gel permeation chromatography}

The molar mass and the degree of sulfation of the polysaccharide are important parameters influencing polyelectrolyte complexes. ${ }^{30}$ The cashew gum has a peak molar mass of $2.3 \times 10^{4} \mathrm{~g} \mathrm{~mol}^{-1}$. The absolute value of the average molar mass of sulfated products can only be determined by GPC if the chromatograph is coupled to a detector such as a multiangle laser light scattering (MALLS) instrument, in which no standards are required to calibrate the column. When other detectors are used, such as a refractive index detector, standards of different molar masses are required. Pullulan is frequently used for polysaccharides. However, this standard is not appropriate for charged polysaccharides due to the chain stiffening and length, as a consequence of electrostatic repulsion.

The GPC chromatograms for CG and sulfated derivatives can be seen in Figure 4. Taking into account that a MALLS detector was not available for this study, the discussion on the molar mass is based on the elution volumes and comparison. A shift to a lower elution volume was observed comparing the curves for $\mathrm{CG}(\mathrm{Ve}=8.84 \mathrm{~mL})$ and CGS6 ( $\mathrm{Ve}=8.74 \mathrm{~mL}$ ). If no chain degradation occurs, the sulfated samples will have a higher hydrodynamic volume and would be expected to elute at a lower volume than the starting polymer due to molar mass increase and repulsion between new charged groups. It is expect a increase in the molar mass due to the introduction of the $-\mathrm{SO}_{3} \mathrm{Na}$ group. In the CGS6 (DS $=0.24$ ), if no degradation

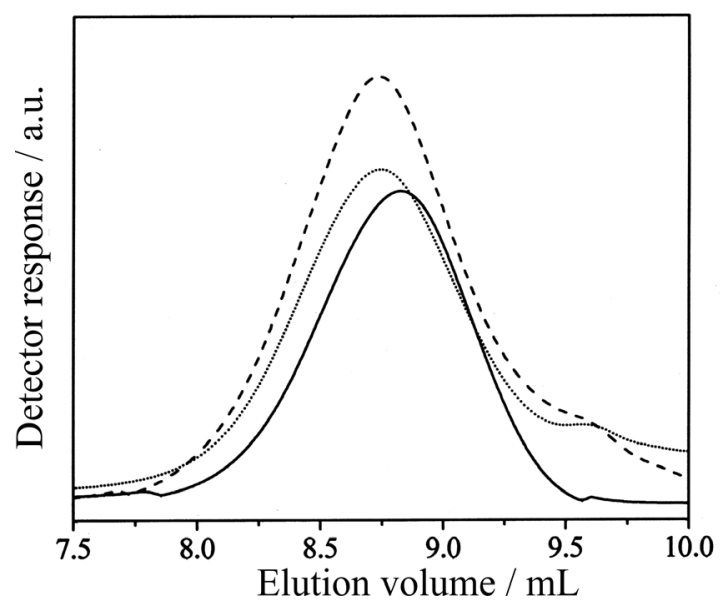

Figure 4. GPC chromatogram of aqueous solutions of unmodified CG (continuous line) and sulfated cashew gums CGS6 (dotted line) and CGS8 (dashed line). occurs, the molar mass increases by around 15\%. This higher molar mass is expected to change the elution volume by more than $0.10 \mathrm{~mL}$. Thus, chain degradation probably occurs. The shoulder at a higher elution volume and the small yield are in agreement with this assumption.

CGS8 showed an elution volume similar to that of CGS6, even with a higher DS (0.88). Since the molar mass and also chain charge increase from CGS6 to CGS8, a higher elution volume was expected. Therefore, the chain degradation in CGS8 is higher than in CGS6. An increase in degradation as the DS increase was also observed in the sulfation of galactan ${ }^{24}$ and lacquer polysaccharide. ${ }^{33}$ Higher degradation with an increasing degree of derivatization was described for carboxymethylation ${ }^{13}$ and oxidation of cashew gum. ${ }^{14}$

Considering that no peak or shoulder at an elution volume comparable with that of the precursor gum was noted in CGS6 or CGS8 chromatogram, no unmodified gum remains. A different result was reported by Mihai et al. ${ }^{28}$ who found that $40 \%$ of the pullulan remains non sulfated in the $\mathrm{SO}_{3}$.py complex at $80{ }^{\circ} \mathrm{C}$ over $4 \mathrm{~h}$. These results were in agreement with the NMR data and the yield values.

Carboxymethylation of cashew gum leads to higher degree of degradation than that observed in the sulfation reaction..$^{13}$ This is an important result when the objective is to prepare PECs, as concluded by Schatz et $a l .^{30}$ in a study on the preparation of PEC using dextran sulfate and chitosan.

\section{Thermal analysis}

The thermogravimetric curves of the cashew gum and sulfated derivatives are shown in Figure 5 and the parameters obtained from the curves in Table 2. The comparison of the curves reveals that the thermal decomposition processes of the CG and CGS samples are different. The first event $\left(\mathrm{T}_{\max } c a .50^{\circ} \mathrm{C}\right)$ is related to water loss and is present in all curves. Cashew gum shows an event at $\mathrm{T}_{\max } 400^{\circ} \mathrm{C}$, which is not present in the case of sulfated samples. CGS gums show a new event at $\mathrm{T}_{\max } 500-520^{\circ} \mathrm{C}$ that is not present in the TGA of the original gum. Similar results were obtained for carboxymethylated cashew gum. ${ }^{34}$ This event is probably related to thermal scission of carbohydrate segments containing sulfate groups, despite of the not proportional mass loss to the degree of sulfation.

The residues of the derivatives CGS6 and CGS8 at $700{ }^{\circ} \mathrm{C}$ increased by 15.8 and $23.9 \%$, respectively, in comparison with the cashew gum residue $(6.4 \%)$. The sulfated gum with higher DS showed the highest residue, as expected. The stability of the derivatives is around $200{ }^{\circ} \mathrm{C}$. 

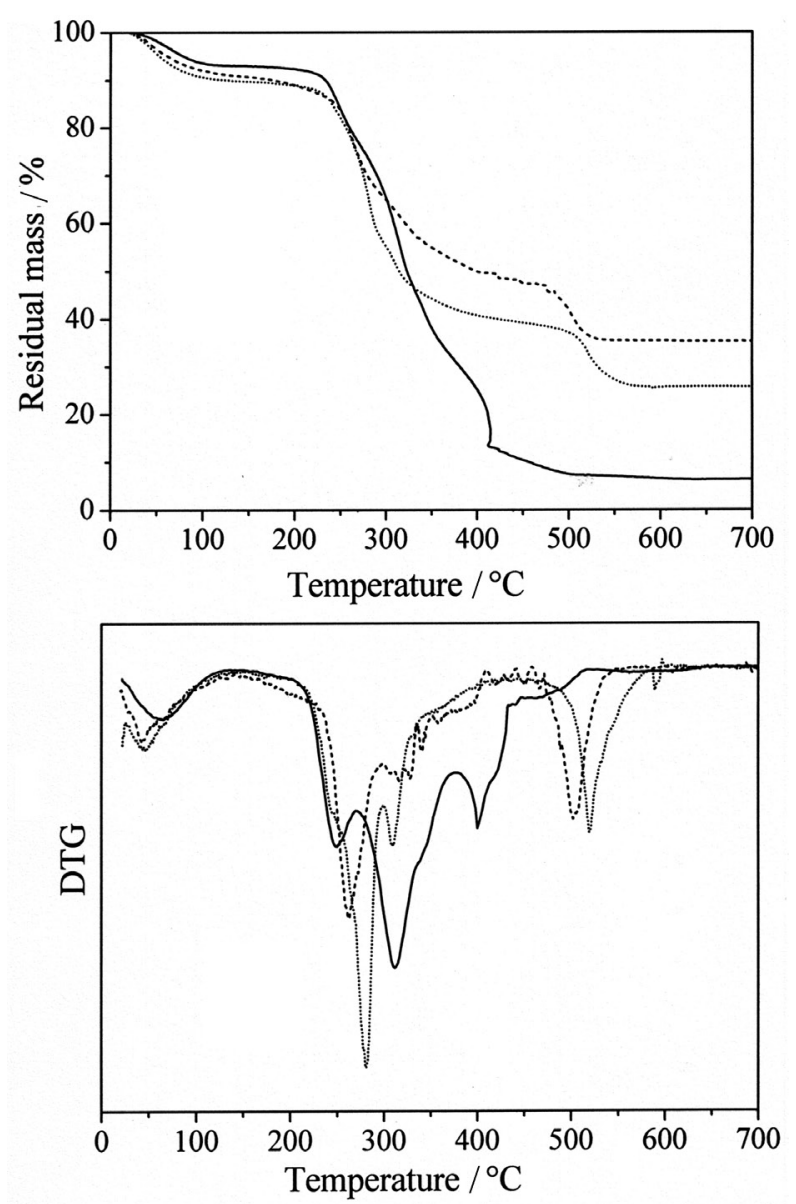

Figure 5. TGA and DTG curves obtained for unmodified CG (continuous line) and sulfated cashew gums CGS6 (dotted line) and CGS8 (dashed line) under synthetic air atmosphere.

\section{Rheological studies}

Aqueous solutions (1\%) of CG and CGS samples have low viscosities (Figure 6). The CGS6 gum curve is very similar to the original gum across the whole shear rate range. However, the sample with higher DS (CGS8) shows a distinct behavior up to a shear rate of $80 \mathrm{~s}^{-1}$. At $30 \mathrm{~s}^{-1}$, for example, the viscosity increase of CGS8 is around 30\% the value for the original gum. At a shear rate above $80 \mathrm{~s}^{-1}$ (Newtonian Plateau), the sulfation promotes an increase in viscosity of only $4 \%$ in comparison to the unmodified CG. The higher negative charge induces more repulsion

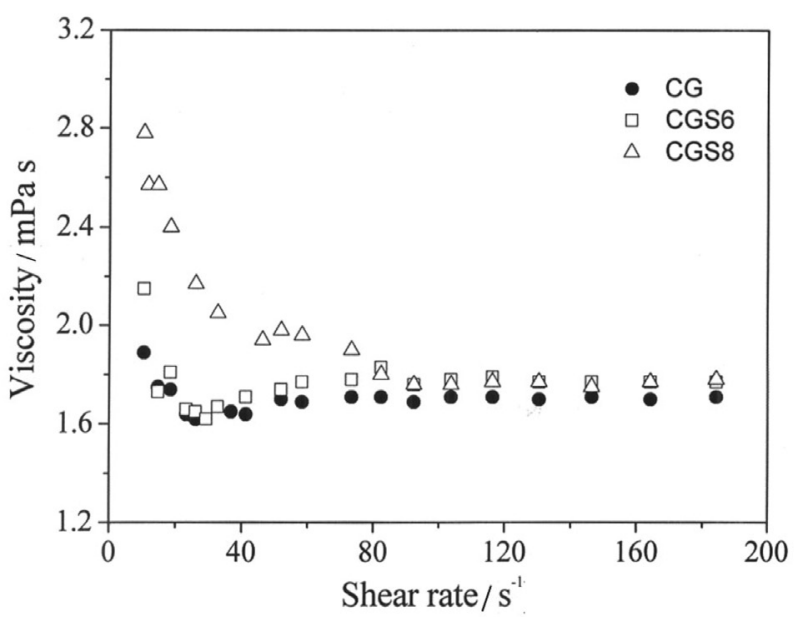

Figure 6. Effect of shear rate on the viscosity of aqueous solutions: unmodified CG, sulfated cashew gums CGS6 and CGS8. Gum concentration $1.0 \%(\mathrm{~m} / \mathrm{v})$ at $25^{\circ} \mathrm{C}$.

between chains and a more expanded macromolecular conformation. However, Geresh et al. ${ }^{29}$ found for sulfated extracellular polysaccharides that the viscosity of sulfated products was lower than that of the starting material, even with no evidence of degradation.

\section{Conclusions}

Three sulfated derivatives of cashew gum were synthesized and characterized. The new sulfate group was detected by FTIR and microanalysis. The sulfation occurs preferentially at the primary carbons of galactose units as observed in the 1D and 2D NMR experiments. The reaction also causes chain degradation, but to a smaller degree than carboxymethylation of CG. A slightly higher viscosity was observed for aqueous solutions of sulfated CG in comparison to the unmodified gum. The sulfation degree is low, but sufficient to increase the ionic charge of the polymer and to improve its polyelectrolytic properties. Sulfated cashew gum offers characteristics suitable for its use in the preparation of nanoparticles of polyelectrolyte complexes. It is more attractive because the cashew gum is a natural, abundant, non-toxic, low cost and regional raw material.

Table 2. Parameters from TGA and DTG curves for the CG and sulfated CGS samples in synthetic air atmosphere at $10^{\circ} \mathrm{C} \mathrm{min}{ }^{-1}$

\begin{tabular}{|c|c|c|c|c|c|c|}
\hline \multirow{2}{*}{ Sample } & \multicolumn{5}{|c|}{ Maximum temperature of event $/{ }^{\circ} \mathrm{C}$} & \multirow{2}{*}{$\begin{array}{l}\text { Residual mass } \\
\text { at } 700{ }^{\circ} \mathrm{C} / \%\end{array}$} \\
\hline & I & II & III & IV & $\mathrm{V}$ & \\
\hline $\mathrm{CG}$ & 55 & 248 & 311 & 400 & - & 6.4 \\
\hline CGS6 & 46 & 291 & 309 & - & 520 & 22.2 \\
\hline CGS8 & 43 & 262 & 316 & - & 502 & 30.3 \\
\hline
\end{tabular}




\section{Supplementary Information}

The DEPT data are provided as supplementary information and available free of charge at http://jbcs.sbq.org.br as PDF file.

\section{Acknowledgements}

The authors acknowledge financial support from Conselho Nacional de Desenvolvimento Científico e Tecnológico (CNPq, Rede Nanoglicobiotec), Instituto Nacional de Ciências e Tecnologia-Materiais Complexos e Funcionais (INOMAT-INCT), Fundação Cearence de Apoio ao Desenvolvimento Científico e Tecnológico (FUNCAP, PPP 04/2006) and Coordenação de Aperfeiçoamento de Pessoal de Nível Superior (CAPES, PRODOC). The authors also thank Centro Nordestino de Aplicação e Uso de Ressonância Magnética Nuclear (CENAUREMN) for recording the NMR spectra.

\section{References}

1. Mackie, W.; Preston, R. D. In Algal Physiology and Biochemistry; Stewart, W. D. P., ed.; Blackwell: Oxford, 1974.

2. Carvalho, L. R.; Roque, N. F.; Quim. Nova. 2000, 23, 757.

3. Nie, X.; Shi, B.; Ding, Y.; Tao, W.; Int. J. Biol. Macromol. 2006, 39, 228.

4. Liu, Y.; Liu, C.; Tan, H.; Zhao, T.; Cao, J.; Wang, F.-S.; Carbohydr. Polym. 2009, 77, 370.

5. Chen, H.; Fan, M.; J. Bioact. Compat. Polym. 2007, 22, 475.

6. Sarmento, B.; Ribeiro, A.; Veiga, F; Ferreira, D.; Neufeld, R.; Biomacromolecules 2007, 8, 3054.

7. Schatz, C.; Bionaz, A.; Lucas, J.-M. ; Pichot, C.; Viton, C.; Domard, A.; Delair, T.; Biomacromolecules 2005, 6, 1642.

8. Bandeira, C. T.; Relatório Técnico da Empresa Brasileira de Pesquisa Agropecuária (EMBRAPA-CNPCa), 6, 1, Brasil, 1991.

9. Cunha, P. L. R.; de Paula, R. C. M.; Feitosa, J. P. A.; Quim. Nova. 2009, 32, 649.

10. de Paula, R. C. M; Rodrigues, J. F.; Carbohydr. Polym. 1995, 26, 177.

11. de Paula, R. C. M.; Heatley, F.; Budd, P. M.; Polym. Int. 1998, 45, 27.

12. Menestrina, J. M.; Iacomini, M.; Jones, C.; Gorin, P. A.; Phytochemistry 1998, 47, 715.

13. Silva, D. A.; de Paula, R. C. M.; Feitosa, J. P. A.; Brito, A. C. F.; Maciel, J. S.; de Paula, H. C. B.; Carbohydr. Polym. 2004, 58, 163.
14. Cunha, P. L. R; Maciel, J. S.; Sierakowski, M. R.; de Paula, R. C. M.; Feitosa, J. P. A.; J. Braz. Chem. Soc. 2007, 18, 85.

15. Silva, D. A.; Maciel, J. S.; Feitosa, J. P. A.; Paula, H. C. B.; de Paula, R. C. M.; J. Mater. Sci. 2010, 45, 5605.

16. de Paula, R. C. M.; Santana, S. A.; Rodrigues, J. F.; Carbohydr. Polym. 2001, 44, 133.

17. O’Neill, A. N.; Can. J. Chem. 1955, 33, 1097.

18. Ono, L.; Wollinger, W.; Rocco, I. M.; Coimbra, T. L. M.; Gorin, P. A. J.; Sierakowski, M. R.; Antiviral Res. 2003, 60, 201.

19. Cremlyn, R. J.; Chlorosulfonic Acid: a Versatile Reagent, Royal Society of Chemistry: Cambridge, 2002.

20. Shi, B. J., Nie, L.-Z., Liu, Y.-L., Tao, W.-Y.; Carbohydr. Polym. 2007, 68, 687.

21. Qiu, H., Tang, W., Tong, X., Ding, K., Zuo, J.; Carbohydr. Res. 2007, 342, 2230.

22. Lu, Y.; Wang, D.; Hu, Y.; Huang, X.; Wang, J.; Carbohydr. Polym. 2008, 71, 180.

23. Wang, Z. M.; Li, L.; Xiao, K.-J.; Wu, J.-J.; Bioresour. Technol. 2009, 100, 1687.

24. Wang, Y.; Peng, Y.; Wei, X.; Yang, Z.; Xiao, J.; Jin, Z.; Int. J. Biol. Macromol. 2010, 46, 270.

25. Melo, M. R. S.; Feitosa, J. P. A.; Freitas, A. L. P.; de Paula, R. C. M.; Carbohydr. Polym. 2002, 49, 491.

26. Ferreira-Neto, A. B.; Pettolino, F.; Cruz-Silva, C. T.; Simas, F. F.; Bacic, A.; Carneito-Leão, A. M. A.; Iacomini, M.; Maurer, J. B. B.; Plant Sci. 2007, 173, 468.

27. Vogl, H.; Paper, D. H.; Franz, G.; Carbohydr. Polym. 2000, 41, 185.

28. Mihai, D.; Mocanu, G.; Carpov, A.; Eur. Polym. J. 2001, 37, 541.

29. Geresh, S.; Mamontov, A.; Weinstein, J.; J. Biochem. Biophys. Meth. 2002, 50, 179.

30. Schatz, C.; Domard, A.; Viton, C.; Pichot, C.; Delair, T.; Biomacromolecules 2004, 5, 1882.

31. Mahner, C.; Lechner, M. D.; Nordmeier, E.; Carbohydr. Res. 2001, 331, 203.

32. Rashid, A.; Mackie, W.; Colquhoun, I. J.; Lamba, D.; Can. J. Chem. 1990, 68, 1122.

33. Yang, J.; Du, Y.; Wen, Y.; Li, T.; Hu, L.; Carbohydr. Polym. 2003, 52, 397.

34. Silva, D. A.; Feitosa, J. P. A.; Maciel, J. S.; Paula, H. C. B.; de Paula, R. C. M.; Carbohydr. Polym. 2006, 66, 16.

Submitted: June 1, 2010

Published online: August 18, 2011 


\section{Preparation and Characterization of a Chemically Sulfated Cashew Gum Polysaccharide}

\section{Érico de Moura Neto, Jeanny da S. Maciel, Pablyana L. R. Cunha, Regina Célia M. de Paula and Judith P. A. Feitosa*}

Departamento de Química Orgânica e Inorgânica, Universidade Federal do Ceará, CP 6021, 60455-760 Fortaleza-CE, Brazil
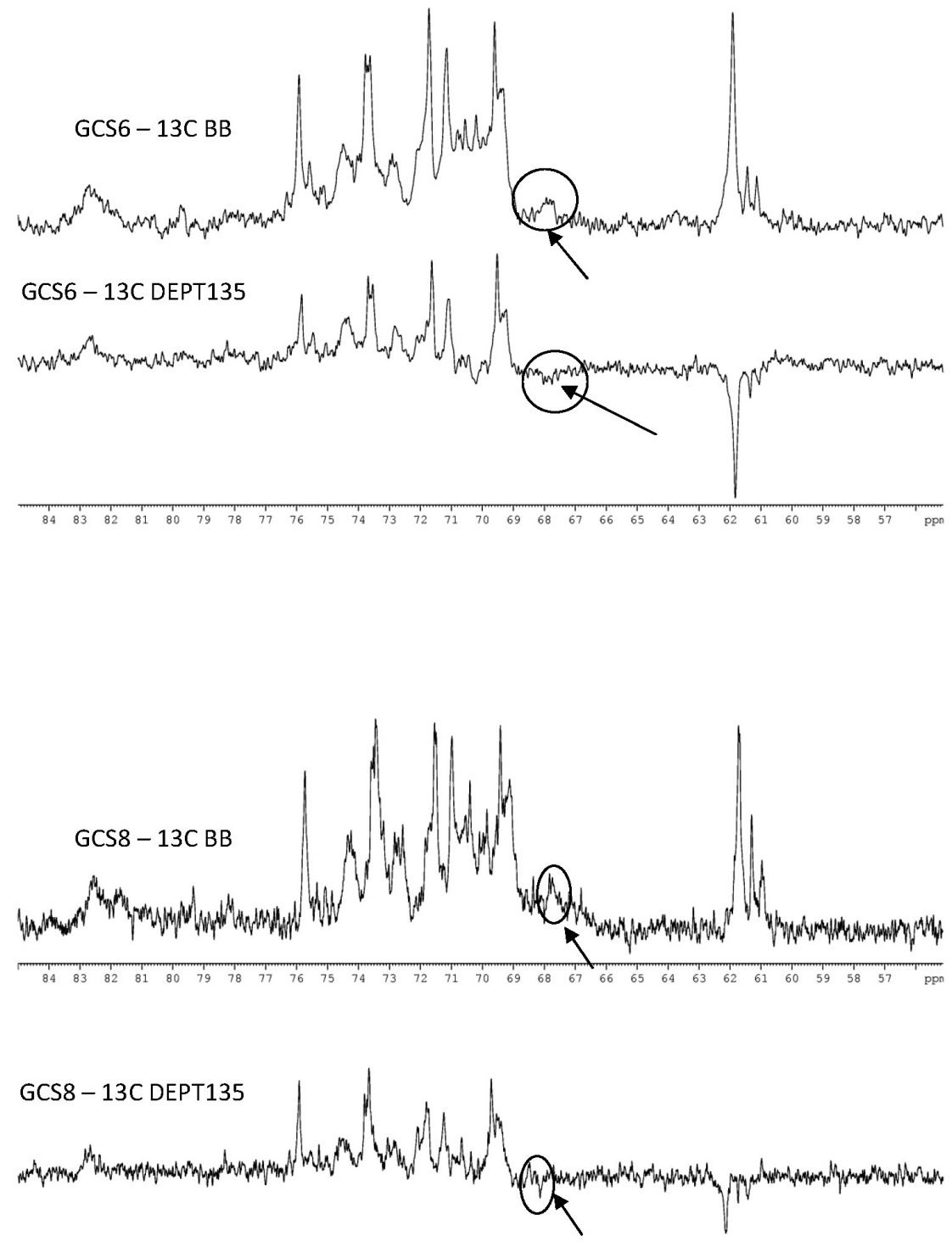

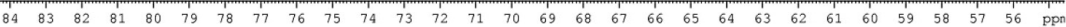

Figure S1. DEPT 135 and BB spectra of sulfated cashew gum (samples GCS6 and GCS8). In sulfated samples (GCS6 and GCS8) spectra a new signal is observed at $\delta 67.8$ in both spectra. The same signal is visualized in opposite amplitude to those of $\mathrm{CH}_{3}$ and $\mathrm{CH}$ signals in DEPT 135 experiment so based on this observation and that substitution of sulfate group on primary carbons causes an increase of chemical shift of 6 to $8 \mathrm{ppm}^{4,23,32}$ we concluded that the sulfate substitution on sulfated cashew gum occur on primary carbons (C-6).

*e-mail: judith@dqoi.ufc.br 